\title{
Chapter 22 \\ Early Life Events and Later Life Health: Twin and Famine Studies
}

\author{
Kaare Christensen
}

\subsection{Introduction}

During more than a decade, the relation between early life conditions and late life health has been one of the major topics in the epidemiological literature. The interest for the connection between early life conditions and later life health is by no means new. As early as in the sixteenth century, Francis Bacon suggested that the nutrition in the womb and the first year of life is very important for later life health. In more recent times, especially the classical paper from 1934 by Kermack et al., and Forsdahl's work in the 1970s (Forsdahl 1977), have been important contributions. However, since the early 1990s, one of the main advocates for the importance of early life conditions for later life health has been David Barker and his group in Southhampton. They revitalized the so-called "fetal origins hypothesis" and have produced an impressive series of papers on the topic. The studies were motivated by this intriguing hypothesis proposed by Barker and co-workers which asserts that a baby's nourishment before and during infancy programmes its susceptibility to cardiovascular diseases as well as several other diseases and adverse outcomes, ranging from diabetes mellitus to cancer and suicide. There is evidence that an association exists between fetal growth and later life health outcomes such as blood pressure and cardiovascular mortality. The key question is, however, whether it is fetal nourishment or other factors such as genes or socioeconomic conditions that cause the association. Some studies suggest that socioeconomic confounding cannot explain the association between fetal growth and cardiovascular mortality (Leon et al. 1998), but they are few, and even fewer studies have evaluated the influence of genetic confounding (Figs. 22.1 and 22.2).

A major concern about the work on the fetal origins hypothesis has been the wide range of exposure proxies and outcomes. Among the exposure proxies measured are

\author{
K. Christensen (四) \\ Institute of Public Health, University of Southern Denmark, Odense, Denmark \\ e-mail: KChristensen@ health.sdu.dk \\ (C) The Author(s) 2019 \\ T. Bengtsson, N. Keilman (eds.), Old and New Perspectives on Mortality \\ Forecasting, Demographic Research Monographs, \\ https://doi.org/10.1007/978-3-030-05075-7_22
}


Fig. 22.1 The fetal origins hypothesis states that the observed negative correlation between birth weight and cardiovascular disease risk is due to early life nutrition
Basic observation:

Birth weight $\sim$ Cardiovascular Diseases (CVD)

Hypothesis:

Early life nutrition

Birth weight

$$
\text { "Programming of }
$$
metabolism"

CVD

Later life overfeeding (?)
Fig. 22.2 Alternative explanations for the observed negative correlation between birth weight and cardiovascular disease risk

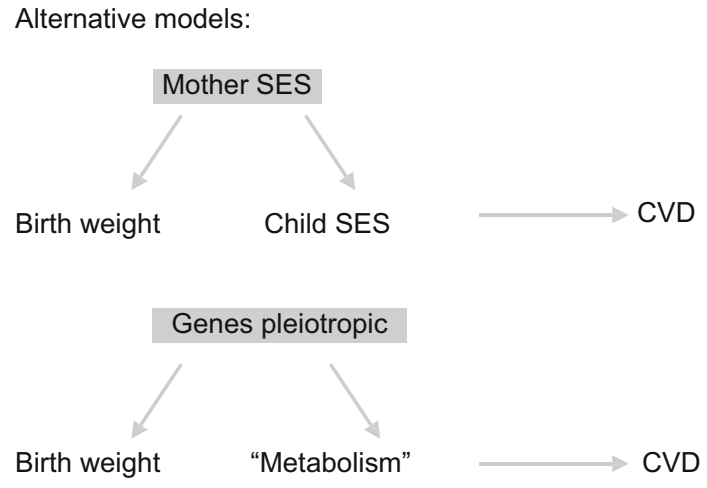

birth weight, birth length, ponderal index, abdominal circumference, and corresponding measurements have been performed at age 1 year. The measurements have been related to outcomes such as survival, cardiovascular diseases, hypertension, diabetes, suicide, and even to getting married (Barker 1994, 1998). Furthermore, these relations have been investigated in hundreds of data sets and very often in subtypes like obese mothers or children with rapid catch-up growth etc. This increases the risk of type 1-errors, i.e. statistically significant random findings, considerably, and has therefore created a certain amount of scepticism (Kramer and Joseph 1996). To avoid some of these problems, in our group at the University of Southern Denmark, we have focused on famine and twin studies which are dealing with extreme conditions in early life, and we have examined how these conditions affect later life health. 


\subsection{Famine Early in Life and Later Life Health}

During the late 1990s, three reports have addressed the influence of prenatal exposure to famine on health in later life. We studied 161,744 individuals born during the 1866-1868 Finnish famine and found, on the basis of a comparison with more than 600,000 individuals born before and after the famine, that nutritional deprivation in utero has no effect on survival in adult life (Kannisto et al. 1997). Stanner et al. (1997) investigated a broad range of coronary heart disease and diabetes mellitus risk factors among 169 people exposed to malnutrition in utero during the siege of Leningrad in 1941-1942 and nearly 400 born before or outside the area of the siege. They found no association between intrauterine malnutrition and glucose intolerance, dyslipidaemia, hypertension, or cardiovascular disease in adulthood. Finally, Ravelli et al. (1998), studied 279 individuals who were exposed to malnutrition in utero during the Dutch hunger winter 1944-1945 and nearly 425 controls born before and after. They found an association between intrauterine exposure to famine and decreased glucose tolerance in adults aged around 50 years. However, it was disappointing that Ravelli and colleagues, among all the suggested outcomes related to fetal nourishment, initially only reported glucose tolerance. Later reports showed that, for example, blood pressure showed no association with blood pressure in the Dutch famine study (Roseboom et al. 1999).

\subsection{Later Life Health for Twins}

Twin studies are especially interesting because twins experience severe growth retardation in the uterus, especially in the third trimester and, furthermore, studies of twins can control for the influence of the mother's socioeconomic status and for the effect of genes. Twins experience considerable retardation in intrauterine growth - for example, they are on average more than $900 \mathrm{~g}$ lighter than single children at birth (MacGillivray et al. 1988; Kline et al. 1989). Phillips (1993) has argued that even small birth weight differences in twins could reflect important differences in intrauterine conditions important for programming of diseases later in life, because the mean birth weight among twins is already considerably lower than in singletons. Therefore, birth weight differences in twins offer a unique opportunity to test the "fetal origins hypothesis".

This also raises a question important to twin researchers: Does the reduced growth pattern in the last trimester make twins more vulnerable in adult life with an increased risk of cardiovascular diseases, diabetes mellitus and other assumingly "programmed" diseases? If so, then twin studies may be a poor model for studying these diseases because the causal field of the diseases could be different from that of singletons. 
If twins are "programmed" due to the considerable growth retardation during the third trimester, one could expect an increased mortality and especially an increased cardiovascular mortality in adulthood for twins compared to the general population. Both a Swedish and our earlier Danish twin study found similar mortality patterns among twins and singletons in adulthood (Vågerö and Leon 1994; Christensen et al. 1995). However, the Swedish twin study (Vågerö and Leon 1994) had a limited follow-up period with no distinction between monozygotic (MZ) and dizygotic (DZ) twins (the latter having slightly higher birth weights on average), and our Danish twin study (Christensen et al. 1995) did not include causes of death.

Therefore we studied cause-specific mortality of 19,986 Danish twin individuals from the birth cohorts 1870-1930 followed from 1952 through 1993 (Christensen et al. 2001). Despite the large sample size and follow-up period, we were not able to detect any difference between twins and the general population with regard to all-cause mortality or cardiovascular mortality. Hence, the intrauterine growth retardation experienced by twins does not result in any "fetal programming" of cardiovascular diseases.

\subsection{Twins and Genetic Confounding}

The potential for genetic confounding in relation to the fetal origins hypothesis has been illustrated by Dunger et al. (1998), who showed that variation in the insulin gene (INS VNTR) is associated with fetal growth. Based on studies of fetal insulin secretion and monogenic diseases, Hattersley and Tooke (1999) proposed that genetically determined insulin resistance contributes substantially to the association of low birth weight with diabetes, hypertension and vascular diseases and named this hypothesis "the fetal insulin hypothesis".

We used the Minnesota Twin Family study (Iacono et al. 1999) to test the potential influence of genetic confounding on the association between birth weight and systolic blood pressure, which is the best documented association between fetal growth and later life health outcome (Barker 1998; Kuh and Ben-Shlomo 1997; Law and Shiell 1996; Taylor et al. 1997). The effect of genetic confounding was evaluated by analysing individual twin data as well as intrapair differences in birth weight and systolic blood pressure. This approach enables controlling for the effect of all genetic factors in monozygotic pairs and on average half of the genetic factors in dizygotic pairs as well as environmental maternal effects. Two recent twin studies (Poulter et al. 1999; Dwyer et al. 1999) using a similar design did not find evidence for a genetic component to the association, but as pointed out in the accompanying editorial (Leon 1999), the number of monozygotic twin pairs in these studies was sparse.

We used the following statistical analysis:

As in Hopper and Seeman (1994), for each twin, $i$, of a pair $(i=1,2)$ let $Y_{i}$ be systolic blood pressure and $\mathrm{X}_{1 \mathrm{i}}=$ birth weight and $\mathrm{X}_{2 \mathrm{i}}=$ current weight. 
Let

$$
Y_{i}=a_{0}+a_{1} X_{1 i}+a_{2} X_{2 i}+E_{i}
$$

where $\mathrm{E}_{\mathrm{i}}$ represents measurement error and effects specific to twin $i$. Each of the coefficients $a_{1}$ and $a_{2}$ represents the strength of a linear association between the blood pressure and a corresponding variable. The intrapair difference is

$$
\mathrm{D}=\mathrm{Y}_{1}-\mathrm{Y}_{2}=\mathrm{a}_{1} \mathrm{D}_{1}+\mathrm{a}_{2} \mathrm{D}_{2}+\mathrm{E}
$$

where $D_{j}=X_{j 1}-X_{j 2}(j=1,2)$ and $E=E_{1}-E_{2}$. From (22.2) it can be seen that the same coefficients $a_{1}, a_{2}$ can be estimated by regressing $D$ against $D_{1}, D_{2}$, and constraining the fitted line to pass through the origin (because (22.2) does not have an intercept term). This second regression approach controls for age, sex and genetic factors (all in monozygotic twins and on average half in dizygotic twins).

From the Minnesota Twin Family Study (Iacono et al. 1999) we included 1311 pairs of adolescent twins, and we found a negative association between birth weight and systolic blood pressure in the overall sample. The regression coefficient after controlling for current weight was $-1.88 \mathrm{~mm} \mathrm{Hg} / \mathrm{kg}$ (SE 0.61), which corresponds to results from previous studies of singleton adolescents. The regression coefficient fell to $-0.64 \mathrm{~mm} \mathrm{Hg} / \mathrm{kg}$ (SE 0.86) when the intrapair analyses were used. The largest reduction was observed among monozygotic twins: from $-2.44 \mathrm{~mm} \mathrm{Hg} / \mathrm{kg}$ (SE 0.75) in the overall monozygotic twin sample to $-1.06 \mathrm{~mm} \mathrm{Hg} / \mathrm{kg}$ (SE 1.14) in the analyses of the within monozygotic pair differences.

\subsection{Overview}

In 2002, Huxley and co-workers published an overview of the available data on the relation between birth weight and later life blood pressure. This relation has been put forward as one of the most consistent and strong evidence of the association between birth weight and later life health. This overview found a clear indication of publication bias as smaller studies reported a large effect while larger studies reported a small effect. Furhermore, it was somewhat disturbing to see that the hypothesisgenerating group consistently reported a larger effect than other research groups.

Huxley et al. (2002) also summarized the available interpair comparison studies in twins and found, based on the above-mentioned study of the Minnesota twins and on other studies, that the confidence interval for the effect estimated by intrapair differences in twins was not different from zero. Even if the largest estimate of the relation between birth weight and blood pressure is accepted, that is to say a $2 \mathrm{~mm}$ $\mathrm{Hg}$ increase in blood pressure for every increase in birth weight by 1 kilo, this is clearly not an important factor on the individual level. Theoretically, it might be an important finding for understanding the etiology of blood pressure, but from a public 
health perspective, the change of $2 \mathrm{~mm} \mathrm{Hg}$ per 1 kilo difference in birth weight would not call for intervention. This view is underlined by the observation by Huxley and colleagues who draw attention to the fact that increase in birth weight also correlates with an increase in weight which might have an even stronger effect on the adult blood pressure than the inverse relation between birth weight and blood pressure, when current weight is controlled for. At present, therefore, too little is known about the effect, and the evidence of the correlation between early life growth and later life health and survival is not strong enough to have any practical importance for forecasting models.

\section{References}

Barker, D. J. P. (1994). Mothers, babies, and disease in later life. London: British Medical Journal Publishing Group.

Barker, D. J. P. (1998). Mothers, babies and health in later life. Edinburgh: Churchill Livingstone.

Christensen, K., Vaupel, J. W., Holm, N. V., \& Yashin, A. I. (1995). Twin mortality after age 6: Fetal origins hypothesis versus twin method. British Medical Journal, 310, 432-436.

Christensen, K., Wienke, A., Skytthe, A., Holm, N. V., Vaupel, J. W., \& Yashin, A. I. (2001). Cardiovascular mortality in twins and the fetal origins hypothesis. Twin Reseach, 4, 344-349.

Dunger, D. B., Ong, K. K., Huxtable, S. J., Sherriff, A., Woods, K. A., Ahmed, M. L., Golding, J., Pembrey, M. E., Ring, S., Bennet, S. T., \& Todd, J. A. (1998). Association of the INS VNTR with size at birth. ALSPAC Study Team. Avon longitudinal study of pregnancy and childhood. Nature Genetics, 19(1), 98-100.

Dwyer, T., Blizzard, L., Morley, R., \& Ponsonby, A. L. (1999). Within pair association between birth weight and blood pressure at age 8 in twins from a cohort study. British Medical Journal, 319(7221), 1325-1329.

Forsdahl, A. (1977). Are poor living conditions in childhood and adolescence an important risk factor for arteriosclerotic heart disease? British Journal of Preventive Social Medicine, 31, 91-95.

Hattersley, A. T., \& Tooke, J. E. (1999). The fetal insulin hypothesis: An alternative explanation of the association of low birthweight with diabetes and vascular disease. Lancet, 353, 1789-1792.

Hopper, J. L., \& Seeman, E. (1994). The bone density of female twins discordant for tobacco use. New England Journal of Medicine, 330, 387-392.

Huxley, R., Neil, A., \& Collins, R. (2002). Unravelling the fetal origins hypothesis: Is there really an inverse association between birthweight and subsequent blood pressure? Lancet, 360(9334), $659-665$.

Iacono, W. G., Carlson, S. R., Taylor, J., Elkins, I. J., \& Macgue, M. (1999). Behavioral disinhibition and the development of substance use disorders: Findings from the Minnesota Twin Family Study. Development and Psyhopathology, 11, 869-900.

Kannisto, V., Christensen, K., \& Vaupel, J. W. (1997). No increased mortality in later life for cohorts born during famine. American Journal of Epidemiology, 145, 987-994.

Kermack, W. O., McKendrick, A. G., \& McKinlay, P. L. (1934). Death rates in Great Britain and Sweden: Some general regularities and their significance. Lancet, 226, 698-703.

Kline, J., Stein, Z., \& Susser, M. (1989). Conception to birth. New York: Oxford University Press.

Kramer, M. S., \& Joseph, K. S. (1996). Enigma of fetal/infant origins hypothesis. Lancet, 348, 1254-1255.

Kuh, D., \& Ben-Shlomo, Y. (1997). Life course approach to chronic disease epidemiology. Tracing the origins of ill-health from early to adult life. Oxford: Oxford University Press. 
Law, C. M., \& Shiell, A. W. (1996). Is blood pressure inversely related to birth weight? The strength of evidence from a systematic review of the literature. Journal of Hypertension, 14, 935-941.

Leon, D. A. (1999). Twins and fetal programming of blood pressure. British Medical Journal, 31, 1313-1314.

Leon, D. A., Lithell, H. O., Vågerö, D., Koupilova, I., Mohsen, R., Berglund, L., Lithell, U.-B., \& McKeigue, P. M. (1998). Reduced fetal growth rate and increased risk of death from ischaemic heart disease: Cohort study of 15,000 Swedish men and women born 1915-29. British Medical Journal, 317, 241-245.

MacGillivray, I., Campbell, D. M., \& Thompson, B. (Eds.). (1988). Twinning and twins. London: Wiley.

Phillips, D. I. (1993). Twin studies in medical research: Can they tell us whether diseases are genetically determined? Lancet, 341, 1008-1009.

Poulter, N. R., Chang, C. L., MacGregor, A. J., Schneider, H., \& Spector, T. D. (1999). Association between birth weight and adult blood pressure in twins: Historical cohort study. British Medical Journal, 319, 1330-1333.

Ravelli, A. C. J., van der Meulen, J. H. P., Michels, R. P. J., Osmond, C., Barker, D. J. P., Hales, C. N., \& Bleker, O. P. (1998). Glucose tolerance in adults after prenatal exposure to famine. Lancet, 351, 173-177.

Roseboom, T. J., van der Meulen, J. H. P., Ravelli, A. J., van Montfrans, G. A., Osmond, C., Barker, D. J. P., \& Bleker, O. (1999). Blood pressure in adults after prenatal exposure to famine. Journal of Hypertension, 17(3), 325-330.

Stanner, S. A., Bulmer, K., Andrès, C., Lantseva, O. E., Borodina, V., Poteen, V. V., \& Yudkin, J. S. (1997). Does malnutrition in utero determine diabetes and coronary heart disease in adulthood? Results from the Leningrad siege study, a cross-sectional study. British Medical Journal, 315, 1342-1349.

Taylor, S. J., Whincup, P. H., Cook, D. G., Papacosta, O., \& Walker, M. (1997). Size at birth and blood pressure: Cross sectional study in 8-11 year old children. British Medical Journal, 314, 475-480.

Vågerö, D., \& Leon, D. (1994). Ischaemic heart disease and low birth weight: A test of the fetalorigins hypothesis from the Swedish Twin Registry. Lancet, 343, 260-263.

Open Access This chapter is licensed under the terms of the Creative Commons Attribution 4.0 International License (http://creativecommons.org/licenses/by/4.0/), which permits use, sharing, adaptation, distribution and reproduction in any medium or format, as long as you give appropriate credit to the original author(s) and the source, provide a link to the Creative Commons license and indicate if changes were made.

The images or other third party material in this chapter are included in the chapter's Creative Commons license, unless indicated otherwise in a credit line to the material. If material is not included in the chapter's Creative Commons license and your intended use is not permitted by statutory regulation or exceeds the permitted use, you will need to obtain permission directly from the copyright holder. 